\title{
The research of small and medium-sized wedding photography enterprise's product types and consumer participation behavior
}

\author{
Wenrong Jiang ${ }^{1,}$, Shijie $\mathrm{He}^{1, \mathrm{~b}}$ \\ ${ }^{1}$ School of Economics and Management, Shanghai Polytechnic University, \\ Pudong New District, Shanghai, China \\ awrjiang@sspu.edu.cn, b690606304@qq.com
}

\begin{abstract}
Keywords: Small and medium-sized wedding photography enterprise; Product types; Consumer participation behavior

Abstract. With the development in wedding photography market in recent years, customer's increasingly demand presents a trend of diversification, customer's demand for the core services also will change small and medium enterprise product type. Through the study of wedding photography business product types and consumer participation behavior, we will explore the potential relationship between the two to help wedding businesses more precisely targeting consumer demands, while designing healthy long-term marketing program to help small and medium enterprises to get better wedding photography development in the fierce competition in the market.
\end{abstract}

\section{Introduction}

With the gradual improvement of people's living standards, people's emphasis also greatly improved on their wedding pictures. This passage takes Anqing City for example, choosing three small and medium sized wedding enterprise to explore, it also assessed in-depth analysis of the competitive situation of the wedding photography industry, product type and internal environment, market demand and customer participation behavior, and did a comprehensive analysis and guidance of the wedding photography industry's marketing strategy, and finally put forward specific policy under the wedding photography industry tide of the Internet network marketing to help small and medium enterprises develop steadily in the fierce competition.

\section{Background and development situation both at home and abroad}

The wedding party custom is different in the United States, before the wedding ceremony the groom can not see the woman's wedding dress, the woman would likely to choose sisters or female friends of the selection of wedding dress, so most couple's wedding photography in western country are only the wedding scene shooting. China is not the same, in addition to providing wedding dress rental service, but also extends the wedding photography industry, providing exclusive enterprise, photographer and wedding-related services. With the social and economic development, people's living standards are increasing, people's consumption demand levels gradually rise from the material demand to spiritual needs, marriage is a particularly important life event of the Chinese people, so the demand in terms of marriage began to happen change, especially for the typical wedding photography.

\section{Investigation of 3 wedding photography enterprises}

The research object: Xu Ming International Wedding Photography, Taiwan Sedan On Photography, Paris Spring Fashion Photography, totally 3 Anqing local typical wedding photography business.

The research method: through the Anhui Photographic Industry Association, we choose the local member of collecting voluntary research Anqing City wedding photography business, by screening the final choice of annual turnover of three similar sized wedding photography business, after the communication with business leaders, we got the first-hand data, these data have high reference 
value of marketing. After the discussion with the professional instructors, we decided select the SPSS software for data analysis.

The following is the content of research and statistics:

Table1 Wedding photography consumer's age distribution

\begin{tabular}{|cl|c|c|c|c|}
\hline & & Frequency & Percent & Valid Percent & Cumulative Percent \\
\hline \multirow{4}{*}{ Valid } & Under 20 & 18 & .8 & .8 & .8 \\
Data & $20-35$ & 1659 & 75 & 75 & 75.8 \\
& $35-55$ & 418 & 18.9 & 18.9 & 94.8 \\
& Above55 & 116 & 5.2 & 5.2 & 100.0 \\
& Total & 2211 & 100.0 & 100.0 & \\
\hline
\end{tabular}

From the consumers age distribution chart, we can see that 20-35 year-old has become the main force in this age end consumer group, accounting for $75 \%$ of the total share, while the 35-55 year-old picture shows consumers account for only $18.9 \%$, over the age of 55 is only $5.2 \%$.
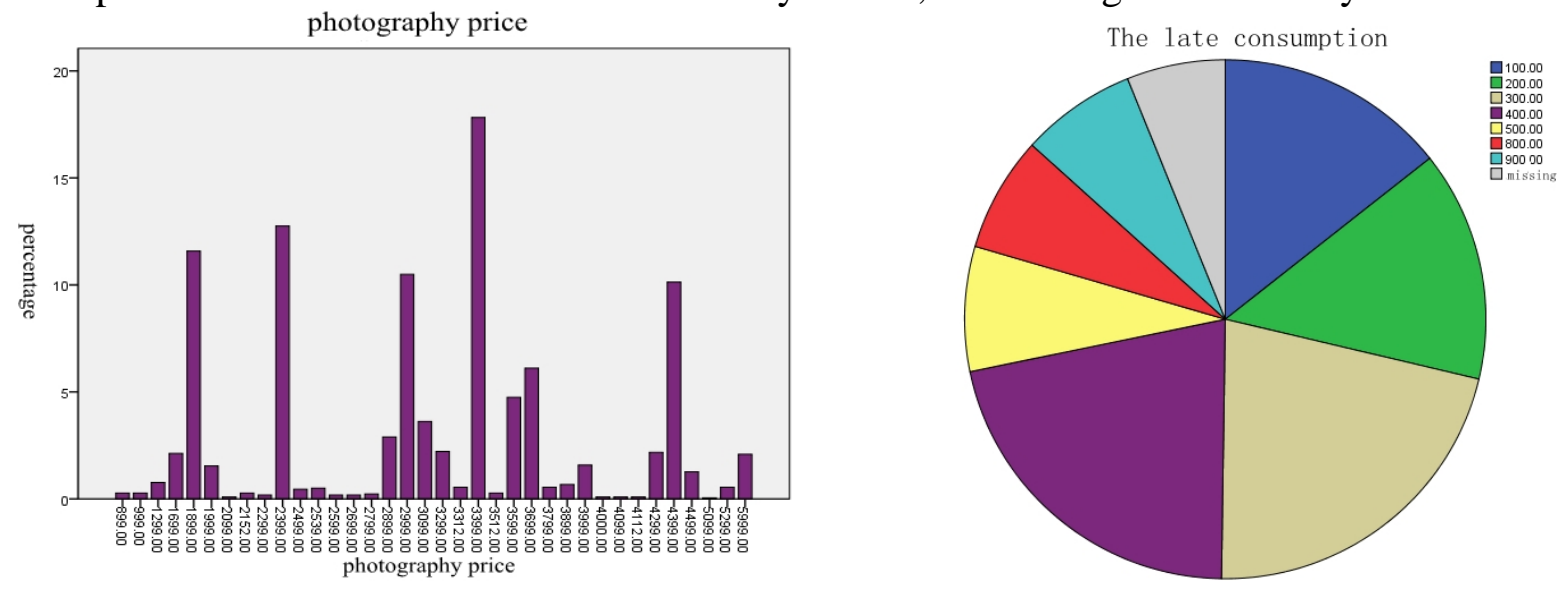

Fig.1 Wedding photography shooting price distribution Fig.2 Consumer distribution of the late consumption

As we can see from the chart, the consumer's choice shot mainly in the low-end package, in 1899-2399 yuan and 2999-3699 yuan the proportion of these two segments of consumers accounted for about $80 \%$, while more than 4,000 yuan sets of high-end department only have few people interested, and that means this result have a significant relationship with the pricing strategy and sales focus.

In addition a very small missing part, we can see the main section includes post-consumer film, CD, etc is the period 100-900 yuan, 500 yuan and above only around $25 \%$ post-consumer, so the latter part of the diversity of digital products and sales strategy is particularly inadequate, how to improve it become a top priority problem.

\section{Anqing City wedding photography small and medium enterprise market positioning analysis}

Wedding photography business in different target markets has different types of customers, some customers value the enterprise provided wedding photography products: Some customers value the company's creative design wedding; there are some other customers value the company launched a unique filming base, also part of the emphasis on customer service store is the attitude of the reception staff, of course, also part of the customer value the price provided by the wedding photography enterprise. Due to the self-limiting conditions, available resources, small and medium sized enterprise can not do everything well, so they should be based on their own resources available for the competitors marketing strategy, develop their own, unique marketing strategy. From this perspective, small and medium wedding accurate and comprehensive analysis of the target market is particularly important. Specific target market segment are analyzed as follows: 
Firstly, the company need to identify potential competitive advantage. Secondly,the company should determine the positioning differentiation. Finally, determining positioning strategy and positioning statements.

\section{Small and medium-sized wedding photography Marketing Strategy}

(1)Small and medium-sized wedding photography enterprises product type

The product refers to anything that can be provided to the market, to meet the desires and needs of some people, including in-kind services, places, organizations and ideas. Modern marketing theory suggests that the overall product concept includes the essence of the product, in the form of products and additional product three levels, is the basis of marketing strategy, because the main consumer target is to buy products, so if companies want to win in the fierce competition in the market, it must first innovative their products, establish a good image of the product. The launch of the product wedding photography in addition to tangible, in fact, is more directly linked to the service and intangible products, Anqing has an increasing competition in the local market in recent years, through sales survey the 3 wedding photo companies began a downward trend in varying degrees, so focus on improving service quality, focus on innovation, developing new products and services, has become a priority for the company.

(2)Small and medium-sized wedding photography enterprises innovation wedding service products strategy

Due to the different consumer enterprises products have different needs, and with the changes in the environment, consumer demand is also constantly updated, so the wedding should place particular emphasis on innovation in products and services, regularly to consumer demand research work, and timely summary of feedback to improve the image of the enterprises, the enterprises to enhance competitiveness, improve business performance enterprises. Service innovation, is to create something new, to establish a differentiated image, to meet the psychological and emotional needs of consumers. Its strong point is that fundamental to customer satisfaction as the center, constantly striving for perfection.

(3)Small and medium-sized wedding photography enterprises Internet marketing strategy

The key lies in the ability to network marketing e-commerce network technology, capacity-enterprises by electronic means of communication with customers, employees and the implementation of network marketing ability to understand. Therefore, analysis of the situation you want to use e-commerce thinking to analyze. Strategic objectives enterprises to be positioned on the basis of the analysis of the situation. It can be a growth indicators, competitive position, management and other areas. It needs to include work on indicators task, quantifiable, time range.

Internet marketing strategy is the integration of science and technology strategy and marketing strategy, in the traditional wedding photography industry has a strategy on the basis of experience, still need to integrate IT strategy (such as the Internet, database, etc.) to achieve business goals. IT strategy primarily for customer relationship management systems, information management systems, payment systems, assessment and tracking system equipment companies such as a series of e-commerce technology implementation plan.

\section{Small and medium-sized wedding photography enterprises turnover analysis and forecast (example: Xuming International Wedding)}

After the analysis of these 3 companies business situation, we have chosen Xuming international wedding photography as an example to forecast the turnover trend in the next three years, in 2015 the company's annual turnover is 1.62 million yuan, basically the same as the turnover in 20141.64 million yuan, a comprehensive update in the product line and double stimulation of network marketing, the number of family and personal photo sets of lines will be increased significantly, 2017 Anhui Lanxi photography base will be completed, the number of travel photography will be greatly increased. With the cooperation with the electricity supplier platform, long-term set of lines 
to go abroad shooting sets will lead the development of the company in 2018 to reach a turnover of 2 million threshold, reaching a record high.

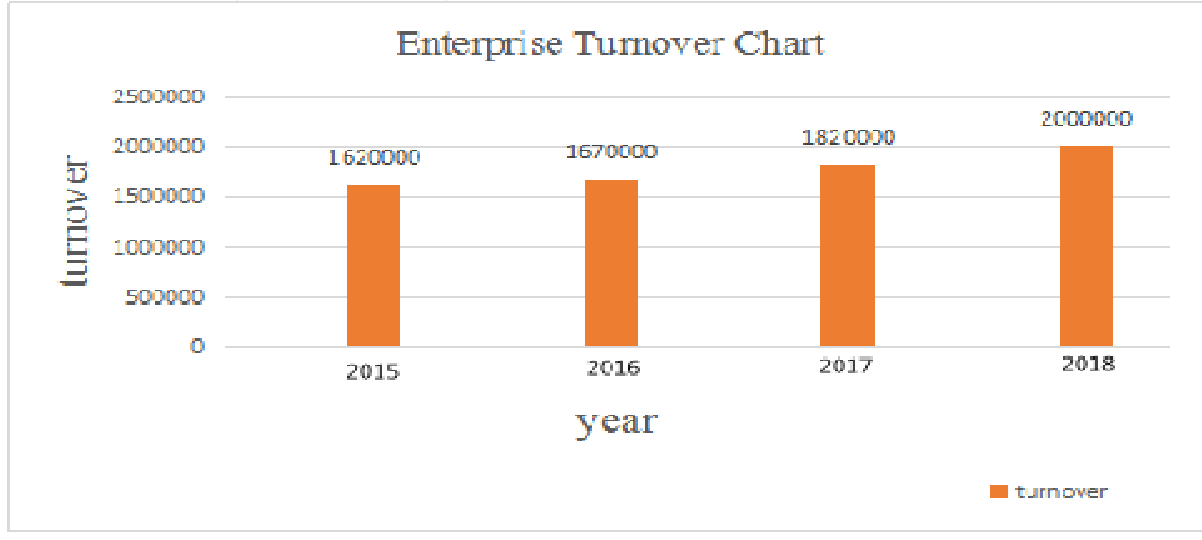

Fig.3 Enterprise Turnover Forecast Chart

\section{Conclusions}

Based on Anqing wedding extensive field surveys, we gathered first-hand information, through questionnaires studio target consumer group, and the data collected were consolidated, after analysis, combined with field investigation conclusions include Anqing sized wedding service marketing process existing problems, combined with the marketing theory of market positioning completed analysis of market positioning studio for studio target market, put forward constructive marketing mix strategy, to a certain extent, help solve the existing studio marketing issues to improve studio image and performance experience.

\section{Acknowledgements}

This work is supported by the Key Disciplines of Computer Science and Technology of Shanghai Polytechnic University under Grant No. XXKZD1604.

\section{References}

[1] Wenrong Jiang, Jian Chen, Wei Tao. The Development of Automotive Interior Sales Website[J]. Communications in Computer and Information Science (Volumes 268), 2011(12):342-348. EI:20122015019844

[2] Wenrong Jiang, Jiajun Tang. The new exploration of network marketing based on S.CN [J]. EEE'14, CSREA PRESS, LAS VEGAS, USA, 2014(7) July 21-24, 2014:107-113.1-60132$268-2$

[3] Wenrong Jiang, Jihong Yan. Implementation of Static Web-Pages Generator Using JavaScript[J]. Applied Mechanics and Materials Vol. 39, 2010(10):588-591.

[4] Zhikun Hu, Wenrong Jiang, Cuihong Wu, Hailan Pan, Jian Chen. The Methods and Analytical Studies of Taobao Stores Promotion[J]. The Ninth Wuhan International Conference on E-Business (WHICEB 2010), Wuhan, China: IEEE Press. 2010(5):118-122.

[5] Wenrong Jiang, Shiwei Lin. Information Technology in the E-commerce Marketing Strategy of OAWAY Website[J]. ECWAC 2013, Wuhan, China: Advanced Materials Research (Volumn 859), 2014(1):551-555

[6] Zhang yan. Ningbo small and Medium-sized Enterprise on -"luxury feast" for Informatization Application[J]. Small and Medium-sized Enterprise on Study. 2008.6: 5-19 
[7] Wenrong Jiang, Jian Chen. Analysis of the E-commerce Website-Jumei Youpin[J]. Advances in Education Sciences, 2015(6), Vol 10, 264-269. 